\title{
Lymphocyte subsets, phytohaemagglutinin responsiveness of blood lymphocytes, and interleukin 2 production in sarcoidosis
}

\author{
E CHAILLEUX, JD BIGNON, MA PEYRAT, A GODARD, JP SOULILLOU
}

From the Service de Pneumologie, Hôpital Nord; Centre de Transfusion Sanguine; and Laboratoire d'Immunologie Clinique (INSERM), Nantes, France

ABSTRACT To test the possibility that T lymphocyte subset imbalance and interleukin 2 ( $\mathrm{IL}_{2}$ ) play a part in the impairment of cellular immune response in sarcoidosis, the proportion of $\mathrm{T}$ lymphocyte subsets in peripheral blood and alveolar lavage fluid from 21 patients with sarcoidosis was studied, monoclonal antibodies OKT3, OKT4, and OKT8 being used. Lectin induced production of $\mathrm{IL}_{2}$ and phytohaemagglutinin (PHA) responsiveness of peripheral blood lymphocytes were investigated. The percentage of both $\mathrm{OKT}^{+}$and $\mathrm{OKT} 4^{+} \mathrm{T}$ lymphocytes was significantly lower in peripheral blood from patients with sarcoidosis than in control subjects (control $63 \%$ and $46 \%)$, more so in patients with chronic sarcoidosis $(44 \%$ and $23 \%)$ than in patients with recent sarcoidosis (56\% and $38 \%$ ). PHA induced $\mathrm{IL}_{2}$ production from peripheral blood lymphocytes did not differ between patients with sarcoidosis and control subjects. There was a significant positive correlation between PHA responsiveness and the percentage of blood $\mathrm{OKT}^{+}$and $\mathrm{OKT}^{+}$cells. Peripheral blood lymphocyte PHA responsiveness was decreased only in patients with an OKT4/OKT8 ratio of less than 1.5. Finally, late addition of exogenous $\mathrm{IL}_{2}$ to the culture medium on day 5 increased $3(\mathrm{H}) \mathrm{Tdr}$ incorporation by PHA stimulated blasts in peripheral blood lymphocytes from normal subjects, but not from those of patients with sarcoidosis. The data suggest that the impairment of cellular immune response in patients with sarcoidosis could in part reflect a decrease in the percentage of blood $\mathrm{T}$ helper lymphocytes and impaired $\mathrm{IL}_{2}$ receptors at the surface of stimulated lymphocytes.

Immunological abnormalities in sarcoidosis arising from cellular and humoral dysfunction include decreased delayed type reactions, a decreased number of circulating $T$ lymphocytes, impaired response of blood mononuclear cells to mitogens, a large number of circulating B lymphocytes, raised serum immunoglobulin concentrations, and the presence of autoantibodies and circulating immune complexes (see ref 1 for review). Alveolar lavage has permitted new insights into these immunological abnormalities, supporting the hypothesis that the immune response is "compartmentalised" in sarcoidosis since the patterns in the lung differ considerably from those in peripheral blood. ${ }^{2}$ Imbalance in

Address for reprint requests: Professor JP Soulillou, Laboratoire d'Immunologie Clinique, Université de Nantes-VER de Médecine, 1 rue G Veil, 44035 Nantes Cedex, France

Accepted 8 March 1985
T lymphocyte subsets has been reported in blood ${ }^{34}$ and lung. ${ }^{5}$ The lung changes are characterised by an alveolitis with an increased number of in situ activated $\mathrm{T}$ lymphocytes, ${ }^{6}$ spontaneously producing lymphokines such as monocyte chemotactic factor? and interleukin $2,{ }^{8}$ and abnormally high local production of immunoglobulins. ${ }^{9} \quad T$ cell growth factor-TCGF or interleukin $2\left(\mathrm{IL}_{2}\right)$-is required for proliferation of activated $\mathrm{T}$ lymphocytes. This lymphokine is produced by activated T cells (mostly $\mathrm{T} 4^{+}$phenotypes) ${ }^{1011}$ and its production is controlled by lymphocyte activated monocytes. ${ }^{12}$ The aim of this study was to analyse the cellular immune response in 21 patients with sarcoidosis, to determine (1) the proportion of $T$ lymphocyte subsets in peripheral blood and alveolar lavage fluid with the help of monoclonal antibodies OKT3 (identifying mature $\mathrm{T}$ cells), OKT4 (identifying the helper subset), and OKT8 (identifying the suppressor- 
Characteristics of patients

\begin{tabular}{|c|c|c|c|c|c|c|c|c|c|}
\hline \multirow[t]{2}{*}{ Group } & \multirow[t]{2}{*}{$\operatorname{Age}^{*}(y)$} & \multirow[t]{2}{*}{$\operatorname{Sex} M / F$} & \multirow{2}{*}{$\begin{array}{l}\text { Smoking history } \\
\text { (smokers/no } \\
\text { smokers) }\end{array}$} & \multirow{2}{*}{$\begin{array}{l}V C(\% \text { of } \\
\text { predicted } \\
\left.\text { normal }^{*}\right)\end{array}$} & \multirow{2}{*}{$\underset{\left(\%^{*}\right)^{\prime}}{F E V}, V C$} & \multirow{2}{*}{$\begin{array}{l}\text { Transfer factor } \\
(\% \text { of predicted } \\
\left.\text { normal }{ }^{*}\right)\end{array}$} & \multicolumn{2}{|c|}{ Radiological stage } & \multirow{2}{*}{$\begin{array}{l}A C E(\text { nmol } \\
\left.\min / \mathrm{ml}^{*}\right)\end{array}$} \\
\hline & & & & & & & 1 & 2 & \\
\hline Recent sarcoidosis & $30.5 \pm 8.5$ & $7 / 4$ & $5 / 6$ & $108(17)$ & $83.1(5.5)$ & $92(29)$ & 7 & 4 & $42.3(14.8)$ \\
\hline \multirow{2}{*}{$\begin{array}{l}\text { Chronic sarcoidosis } \\
\quad(\mathrm{n}=10)\end{array}$} & $44 \pm 14$ & $6 / 4$ & $1 / 8$ & $90(15)$ & $74.3(9.1)$ & $81(32)$ & 0 & 10 & $42.5(15.3)$ \\
\hline & $p<0.02$ & NS & NS & $\mathrm{p}<0.02$ & $\mathrm{p}<0.02$ & NS & \multicolumn{2}{|l|}{$\mathrm{p}<0.01$} & NS \\
\hline
\end{tabular}

*Means with standard deviations in parentheses.

(FEV - forced expiratory volume in one second; VC-vital capacity; ACE = angiotensin converting enzyme).

cytotoxic subset); (2) the in vitro production of interleukin 2 by peripheral blood lymphocytes stimulated by phytohaemagglutinin (PHA); and (3) the effect of exogenous semipurified interleukin 2 on PHA blasts and the effect of interleukin $1\left(\mathrm{IL}_{1}\right)$ and indomethacin on interleukin 2 production and PHA induced responsiveness.

\section{Methods}

\section{PATIENTS}

The diagnosis of sarcoidosis was established in 21 patients according to clinical and histological criteria, which included a bronchial, lung or sublingual gland biopsy specimen showing non-caseating epithelioid granulomas. Patients were divided into two groups according to disease duration: 11 patients with disease of under three months' duration were considered as having recent sarcoidosis and 10 patients with disease of over 18 months' duration (maximum 65 months') as having chronic sarcoidosis. Details of age, sex, smoking, radiological staging, and functional data in the two groups are shown in the table. Patients with chronic sarcoidosis were older, were all classified as having stage II disease radiographically (versus only four of the "recent" patients), and had greater impairment of respiratory function. Blood angiotensin converting enzyme (ACE) activity was significantly and similarly increased in the two groups. All but one patient with chronic sarcoidosis had received corticosteroid treatment with an initial prednisone dose of 0.5 $\mathrm{mg} / \mathbf{k g}$ for 6-48 months. Four patients were receiving prednisone at the time of the study $(2.5,5,10$, and $20 \mathrm{mg}$ a day respectively).

\section{LABORATORY METHODS}

\section{Isolation and counting of lymphocytes}

Bronchoalveolar lavage was performed in all patients by infusion and aspiration of four $50 \mathrm{ml}$ aliquots of sterile $0.9 \%$ saline through the channel of a fibreoptic bronchoscope passed transnasally and wedged in a subsegmental bronchus of the right middle lobe or lingula after xylocaine anaesthesia of the upper respiratory tract and bronchi. The fluid was filtered through two layers of sterile gauze and transported in ice. After evaluation of cell number and differential count, the lavage fluid was centrifuged at $1000 \mathrm{~g}$ for 10 minutes. The cell pellet was then washed in Hanks solution and macrophages were eliminated by glass (Petri dishes) adherence. Final non-adherent cell suspensions were adjusted to $10^{6}$ cells $/ \mathrm{ml}$ before counting of lymphocyte subsets. Peripheral blood lymphocytes were obtained from heparinised blood by sedimentation on Ficoll-Hypaque and washed twice. Peripheral blood lymphocytes were then frozen in liquid nitrogen until used.

The whole $T$ lymphocyte population was evaluated by the technique of sensitised (EAET - treated by ethylamino isothiouronium) sheep red cell rosettes. $^{13}$ Monoclonal antibodies of the orthodiagnostic series were used to identify mature T cells (OKT3), helper subsets (OKT4), and suppressor-cytotoxic subsets (OKT8). Briefly, after 30 minutes' incubation at $4^{\circ} \mathrm{C} 200 \mu \mathrm{l}$ of a $5 \times 10^{3}$ cells $/ \mathrm{mm}^{3}$ suspension were mixed with $5 \mu$ l of monoclonal antibody and washed three times in isotonic buffer. Fluoresceinated goat antimouse antiglobulin, $100 \mu$ l, was then added. After a further 30 minutes' incubation at $4^{\circ} \mathrm{C}$ the fluorescent cell count was carried out on 200 cells under ultraviolet microscopy. B cells were distinguished by surface membrane immunoglobulins with the aid of fluorescein conjugated $F(a b)_{2}$ fragments of goat antihuman immunoglobulin. The number of labelled cells was determined by ultraviolet microscopy. Normal values were established from blood from 35 healthy control subjects.

\section{Assessment of interleukin 2 production from peripheral blood lymphocytes of patients with sarcoidosis}

Thawed peripheral blood lymphocytes were routinely checked for viability ( $>90 \%$ required) and adjusted to $1.10 \% \mathrm{ml}$ in $1 \%$ AB human sera supplemented Dulbeco Eagle culture, Medium (DEM) to which fresh glutamine, penicillin $(1 \mathrm{U} / \mathrm{ml})$, and streptomycin $(100 \mu \mathrm{g} / \mathrm{ml})$ had been added. Cultures were performed in vertical $25 \mathrm{ml}$ Falcon tissue cul- 
ture flasks in $5 \%$ carbon dioxide at $37^{\circ} \mathrm{C}$ for 48 hours in the presence of $1 \mu \mathrm{g} / \mathrm{ml}$ of PHA-P (Difco). Culture supernatants were then harvested and kept at $4^{\circ} \mathrm{C}$ until assayed for $\mathrm{IL}_{2}$ activity.

Interleukin 2 assay The amount of $\mathrm{IL}_{2}$ contained in the supernatant of PHA stimulated blood lymphocytes was assayed on $\mathrm{IL}_{2}$ dependent concanavallin $\mathrm{A}$ (con-A) blasts. Briefly, con-A blasts $\left(10^{4} /\right.$ well $)$ were incubated in 96 wells $(0.2 \mathrm{ml})$ of tissue culture microplates in the presence of $\log ^{3}$ dilution of either a reference $\mathrm{IL}_{2}$ source containing 10 units $/ \mathrm{ml}$ of $\mathrm{IL}_{2}$ or the supernatant of control and sarcoidosis blood lymphocytes stimulated by PHA. After 48 hours' culture, $0.25 \mu \mathrm{Ci}$ tritiated thymidine (Amersham, $\mathrm{SA}=23 \mathrm{Ci} / \mathrm{ml}$ ) was added to each well. The cells were harvested 12 hours later with a Skatron multisample harvester and counted for radioactivity. Results are given as units of $\mathrm{IL}_{2} / \mathrm{ml}$ and as the average amount of tritiated thymidine incorporated in the presence of the blood lymphocyte supernatants at various dilutions. In this assay con- $\mathrm{A}$ blasts gave equally good $\mathrm{IL}_{2}$ measurement as a $C T \mathrm{IL}_{2}$ murine cell line when compared in a cross evaluation. ${ }^{14}$

Purified interleukin 2 Purified $\mathrm{IL}_{2}$ (PHA free) was obtained from the supernatant of PHA stimulated lymphocytes precipitated by $80 \%$ saturation ammonium sulphate and run on an ultragel (ACA 54) column. ${ }^{15}$ The $\mathrm{IL}_{2}$ that was eluted in the 2325000 dalton molecular weight fraction was further concentrated, dialysed against phosphate buffered saline, assayed for $\mathrm{IL}_{2}$ activity, and used at a final concentration of 5 units $/ \mathrm{ml}$.

PHA stimulation Peripheral blood lymphocytes were studied for tritiated thymidine incorporation before and after PHA stimulation in microplates. In these experiments $10^{5}$ blood lymphocytes were incubated for two or five days in $0.1 \mathrm{ml}$ of RPMI 16-40 supplemented with $10 \%$ human $\mathrm{AB}$ sera and $1 \mu \mathrm{g}$ of PHA-P. Purified $\mathrm{IL}_{2}$ was added to the culture wells, either for the total duration of culture in the case of 48 hour stimulation by PHA or only for the last 24 hours of the culture, to assess the presence of receptor, in the case of five day stimulation.

Interleukin 1 and indomethacin Mitogenic (PHA) responsiveness with or without addition of exogenous purified $\mathrm{IL}_{2}$ of either sarcoidosis or control blood lymphocytes was studied in the presence or absence of $\mathrm{IL}_{1}$ (kindly provided by $\mathrm{C}$ Damais, Institut Pasteur, Paris). $\mathrm{IL}_{1}$ was obtained by muranyl dipeptide stimulation of human macrophages. ${ }^{16}$ Supernatant containing $\mathrm{IL}_{1}$ was free of $\mathrm{IL}_{2}$ in the quantitative $\mathrm{IL}_{2}$ assay previously described. The supernatant containing $\mathrm{IL}_{1}$ was added at an optimal final concentration of $10 \%(v / v)$ to the various P-PHA stimulated blood lymphocytes. Similarly, $\mathrm{IL}_{2}$ production by both patient and control blood lymphocytes was studied in the presence and in the absence of exogenous $\mathrm{IL}_{1}(10 \% \mathrm{v} / \mathrm{v})$ in the culture. Indomethacin (Sigma) was used at a concentration of $2 \mu \mathrm{g} / \mathrm{ml}$ in the culture medium.

\section{Results}

Total lymphocytes, E rosetting lymphocytes, and Sm Ig positive mononuclear cells

Blood Although patients with sarcoidosis had a lower level of E rosetting lymphocytes (68.2(10)\%) $v(73(8) \%)$ the difference was not significant. They showed significantly more surface membrane immunoglobulin positive $\left(\mathrm{Sm} \mathrm{Ig}^{+}\right)$cells $(24.3$ (10)\%) than did normal controls (20 (5)\%) (p < $0.5)$. When the data were expressed as absolute values to take account of the number of lymphocytes per $\mathrm{mm}^{3}$, the patients with sarcoidosis showed a significant decrease in the total number of $\mathrm{E}^{+}$lymphocytes $(p<0.01)$. The total number of $\mathrm{Sm} \mathrm{Ig}^{+}$ lymphocytes showed no further increase.

Bronchoalveolar lavage Lymphocytes represented (14.4 (10.4)\%) and (14.9 (5.8)\%) of the mononuclear cells harvested from patients with recent and chronic sarcoidosis respectively and $E$ rosetting cells (75.6(14.9)\%) and (78.8 (9.9)\%). When the results were expressed as absolute numbers from the total
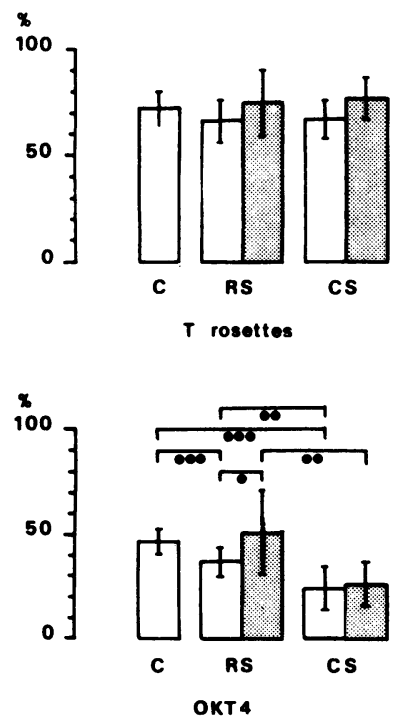
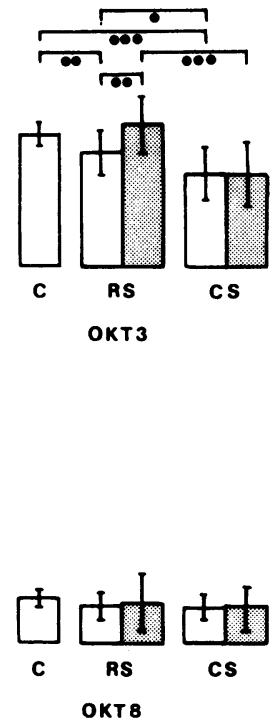

Fig 1 Surface markers of lymphocytes from blood (white columns) and lavage fuid (hatched columns) in control subjects $(C)$, patients with recent sarcoidosis (RS), and patients with chronic sarcoidosis (CS). $\bullet p$

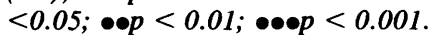




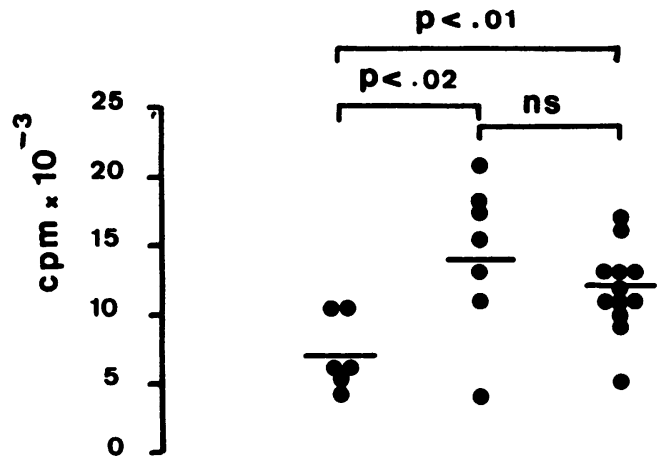

\section{T4/T8 T4/T8 $\leqslant 1.5 \geqslant 1.5$ Controls \\ Patients}

Fig 2 Phytohaemagglutinin responsiveness of the lymphocytes of patients with sarcoidosis (interleukin 2 added during the last 24 hours of culture).

number of cells harvested in the lavage fluid, patients with recent and chronic sarcoidosis had a similar number of lymphocytes and $E$ rosetting lymphocytes.

OKT $(T 3, T 4, T 8)$ cell surface markers (fig 1) Blood The percentages of OKT3 ${ }^{+}$lymphocytes from patients with sarcoidosis $(55.7$ (10)) for recent, (44 (12.4) for chronic) were significantly lower than those from normal controls $(63(6): p<$ 0.01 ). In addition, $\mathrm{OKT}^{+}$lymphocytes were significantly lower in patients with chronic than in those with recent sarcoidosis $(p<0.05)$.

The percentage of $\mathrm{OKT}_{4}{ }^{+}$cells in blood was decreased in patients with both recent (37.6(6.9); $\mathrm{p}$ $<0.001)$ and chronic sarcoidosis (23.2 (10.4); $\mathrm{p}<$ 0.001 ), but more pronounced in the chronic form ( $p$ $<0.01$ ).

The percentage of $\mathrm{OKT}^{+}$cells in blood was slightly but significantly lower in the patients with sarcoidosis than in normal controls $(p<0.05)$, with no difference between patients with chronic and recent disease. Only patients with chronic sarcoidosis had a significantly low $\mathrm{OKT}^{+} / \mathrm{OKT}^{+}$ ratio $(1.3(0.4) ; p<0.001)$. The findings were similar when the data were expressed as absolute values to take the lymphopenia already noted into account (details not given).

Bronchoalveolar lavage fuid The percentage of $\mathrm{OKT}^{+}$cells was higher in lavage fluid than in blood $(67.3(12.6) v 55.7(10) ; \mathrm{p}<0.01$, paired $t$ test) (fig 1 ) in patients with recent sarcoidosis, but not in those with chronic sarcoidosis. OKT4 ${ }^{+}$cells were also more frequent in lavage fluid than in blood from patients with recent sarcoidosis $(50.4$ (19) $v 37.6$ (6.9); $<<0.05)$, but the two counts were similar in chronic sarcoidosis. The percentage of $\mathrm{OKT}^{+}$cells was similar in lavage fluid and in blood in patients with recent and chronic sarcoidosis. Thus a high $\mathrm{OKT}^{+} / \mathrm{OKT} 8^{+}$ratio was found in lavage fluid from patients with recent sarcoidosis $(6.5(6.4))$, but not in that from patients with chronic sarcoidosis (1.7 (1.2)). Again, expressing the data as absolute number of cells gave similar results. In addition, the $\mathrm{OKT}^{+} / \mathrm{EAET}^{+}$ratio was significantly lower $(\mathrm{p}<$

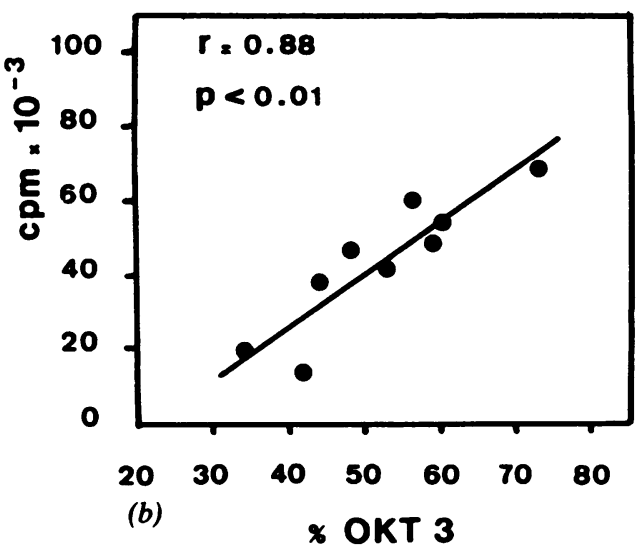

Fig 3 Correlation between phytohaemagglutinin (PHA) responsiveness and $\mathrm{OKT} 3^{+}-\mathrm{OKT} 4^{+}$cell surface markers in peripheral blood lymphocytes of sarcoidosis patients: (a) two days' culture and (b) five days' culture with PHA. 
0.05 ) in both blood and lavage fluid in patients with chronic sarcoidosis.

\section{Interleukin 2}

Interleukin 2 production from lectin stimulated peripheral blood lymphocytes was similar in 14 patients with sarcoidosis and normal controls (4.9 (2.3) $v 3.7(2) \mathrm{U} / \mathrm{ml}$ ). Addition of interleukin 1 or indomethacin did not alter the yield of interleukin 2 in either group. Patients receiving corticosteroids had significantly lower interleukin 2 production $(0.2$ (0.45) v 4.9 (3.4) $\mathrm{U} / \mathrm{ml} ; \mathrm{p}<0.05)$.

\section{Spontaneous and mitogenic blastogenesis}

Peripheral blood lymphocyte incorporation of tritiated thymidine measured after two or five days of "spontaneous" or lectin (PHA) stimulated culture did not differ between patients with sarcoidosis $(\mathrm{n}=$ $14)$ and control subjects $(n=11)$. Addition of $I_{1}$ or indomethacin to the culture did not modify the growth of blood lymphocytes from either patients or normal subjects. When $\mathrm{IL}_{2}$ was added to the medium on day 5 of the PHA stimulated culture, there was a borderline increase in incorporation of tritiated thymidine in lymphocytes from normal subjects $(p<0.05)$, but no effect on those from patients (fig 2).

\section{Correlation between blastogenesis and percentages of lymphocyte subsets}

There was a significant correlation between PHA responsiveness and the level of $\mathrm{T}^{+}$or $\mathrm{T}^{+}$lymphocyte subpopulations when corticosteroid treated patients were excluded: tritiated thymidine incorporation correlated after two days of culture with the percentage of OKT4 $4^{+}$cells $(\mathrm{r}=0.85, \mathrm{p}<0.01)$, and after five days with the percentage of OKT ${ }^{+}$cells $(r$ $=0.88, \mathrm{p}<0.001$ ) (fig 3).

When patients were classified according to the T4/T8 blood ratio decrease in PHA responsiveness was significantly lower in patients with a low ratio $(<1.5)$ than patients with a $\mathrm{T} 4 / \mathrm{T} 8$ ratio closer to normal values $(>1.5)$.

\section{Discussion}

The most striking feature of OKT subpopulation studies in sarcoidosis is the increase in the proportion of $\mathrm{OKT}_{4}{ }^{+}$cells and OKT4/OKT8 ratios in bronchoalveolar lavage fluid in patients with acute sarcoidosis. ${ }^{517-19}$ Our results in patients with recent sarcoidosis are in agreement with these reports. Data concerning the proportions of lymphocyte subsets in blood are more contradictory: the percentage of $\mathrm{OKT}^{+}$cells and $\mathrm{OKT} 4^{+}$cells has usually been found to be decreased, ${ }^{17}{ }^{20}$ whereas the proportion of $\mathrm{OKT}^{+}$cells has been reported as both high ${ }^{5}$ and low, ${ }^{1720}$ with the OKT4/OKT8 ratio either low or normal. Our results for patients with chronic sarcoidosis show a decreased percentage of OKT3 ${ }^{+}$ and $\mathrm{OKT}^{+}{ }^{+}$cells in both blood and lavage fluid. Corticosteroids may decrease the percentage of $\mathrm{OKT}^{+}{ }^{+}$cells, ${ }^{21}$ though in our study there was no difference in the percentage of $\mathrm{OKT}_{3}{ }^{+}$and $\mathrm{OKT} 4^{+}$ cells between patients receiving and not receiving corticosteroids.

A depressed peripheral blood lymphocyte proliferative response to polyclonal mitogens such as PHA in sarcoidosis has been described by previous authors. ${ }^{\prime}$ The decreased proliferative response might be due to an intrinsic defect in sarcoid lymphocytes, ${ }^{22}$ to factors inhibiting mitogen response, ${ }^{23}$ or to antilymphocyte antibodies. ${ }^{24}$ Alterations in the distribution of helper and suppressor lymphocyte subpopulations have also been described, ${ }^{34}$ and an interaction between immune complexes and $T$ suppressor cells has been suggested. ${ }^{25}$ High suppressor activity in sarcoidosis could derive from prostaglandin secretion by monocytes, since for some investigators ${ }^{26}$ removal of the adherent cell population from peripheral blood mononuclear cells as well as addition of indomethacin to culture increased the lymphocyte response to PHA. Our results did not show a significant decrease in PHA responsiveness in the patients with sarcoidosis as a whole. When patients were classified according to their T4/T8 ratio, however, those with a low ratio $(<1.5)$ had less PHA responsiveness than those with a T4/T8 ratio closer to normal values $(>1.5)$. This discrepancy in PHA responsiveness could be related to differences in disease activity since, on the basis of lavage lymphocyte counts, our patients had mainly low intensity alveolitis. ${ }^{2}$

Pinkston et al have shown that lung $\mathrm{T}$ lymphocytes of patients with sarcoidosis and high intensity alveolitis spontaneously release interleukin 2 , which could have a crucial role in increasing the number of lung $\mathrm{T}$ cells in active pulmonary sarcoidosis. ${ }^{8}$ Our study, restricted to interleukin 2 release by lectin stimulated blood lymphocytes, showed that after PHA stimulation lymphocytes from patients and controls produced similar amounts of interleukin 2 . This suggests that defect in endogenous interleukin 2 production is not a major factor in the impaired mitogenic response in sarcoidosis since interleukin 2 has been shown to be necessary for lectin induced proliferation. ${ }^{10}$ Moreover, late addition of exogenous interleukin 2 to the culture medium of PHA stimulated blasts on day 5 increased incorporation of tritrated thymidine in normal individuals but not in patients with sarcoidosis, suggesting that interleukin 2 receptors at the surface of lectin stimulated 
blast cells might be impaired in sarcoidosis. This hypothesis requires further study, with direct binding of labelled interleukin 2 on PHA blasts from patients and normal subjects.

This work was supported in part by a grant from the Centre National de la Recherche Scientifique. We thank Mrs Marie-Therese Guillet for her help in preparing the manuscript.

\section{References}

1 Daniele RP, Dauber JH, Rossman MD. Immunologic abnormalities in sarcoidosis. Ann Intern Med 1980;92:406-16.

2 Crystal RG, Roberts WC, Hunninghake GW, Gadek JE, Fulmer JD, Line BR. Pulmonary sarcoidosis: a disease characterized and perpetuated by activated lung lymphocytes. Ann Intern Med 1981;94:73-94.

3 Katz P, Haynes BF, Fauci AS. Alteration of T-lymphocyte subpopulations in sarcoidosis. Clin Immunol Immunopathol 1978;10:350-4.

4 Semenzato G, Pezutto A, Agostini C, Gasparetto G, Cipriani A. Immunoregulation in sarcoidosis. Clin Immunol Immunopathol 1981;19:416-27.

5 Hunninghake GW, Crystal RG. Pulmonary sarcoidosis. A disorder mediated by excess helper T-lymphocyte activity at sites of disease activity. $N$ Engl J Med 1981;305:429-34.

6 Hunninghake GW, Fulmer JD, Young RC, Gadek JE, Crystal RG. Localization of the immune response in sarcoidosis. Am Rev Respir Dis 1979;120:49-57.

7 Hunninghake GW, Gadek JE, Young RC, Kawanami O, Ferrans VJ, Crystal RG. Maintenance of granuloma formation in pulmonary sarcoidosis by T-lymphocytes within the lung. $N$ Engl J Med 1980;302:594-8.

8 Pinkston P, Bitterman PB, Crystal RG. Spontaneous release of interleukin- 2 by lung $\mathrm{T}$-lymphocytes in active pulmonary sarcoidosis. $N$ Engl $J$ Med 1983;308: 793-800.

9 Hunninghake GW, Crystal RG. Mechanisms of hypergammaglobulinemia in pulmonary sarcoidosis. $J$ Clin Invest 1981;67:86-92.

10 Ruscetti FW, Gallo SR. Human T-lymphocyte growth factor: regulation of growth and function of T-lymphocytes. Blood 1981;57:379-94.

11 Reinherz EL, Kung PM, Brard JM, Goldstein G, Schlossmann SF. Helper $\mathrm{T}_{4}^{+} \mathrm{T}$ cell requirements for generation of helper factor in man: analysis of the subsets involved. J Immunol 1980;124:1883-7.

12 Smith KA, Lachman LB, Oppenheim JJ, Favata MF.
The functional relationship of interleukins. $J$ Exp Med 1980;151: 1551-6.

13 Madsen M, Johnsen ME. A methodological study of E-rosette formation using AET-treated sheep red blood cells. J Immunol Methods 1979;27:61-74.

14 Bertoglio F, Godard A, Soulillou JP, et al. First French workshop on standardization of human IL, joint report. Lymphokine Research 1982;1:121-7.

15 Godard A, Naulet J, Peyrat MA, et al. Preparative two steps purification of human $\mathrm{IL}_{2}$ by HPLC and hydrophobic affinity chromatography. J Immunol Methods 1984; 70:233-39.

16 Damais C, Rivaud G, Parant P, Gerota J, Chedid C. Production of lymphocyte activating factors in the absence of endogeneous pyrogens by rabbit a-human leukocytes stimulated by MDP.J Immunol Pharmacol 1982;4:451-61.

17 Ginns LC, Goldenheim PD, Burton RC, et al. T-lymphocyte subsets in peripheral blood and lung lavage in idiopathic pulmonary fibrosis and sarcoidosis: analysis by monoclonal antibodies and flow cytometry. Clin Immunol Immunopathol 1982;25:11-20.

18 Boyer J, Sohaleh G, Frobert Y, et al. Typage par les anticorps monoclonaux des sous-populations lymphocytaires $\mathrm{T}$ du sang et du lavage bronchoalvéolaire (LBA) au cours de la sarcoidose pulmonaire. $\operatorname{Rev}$ Fr Mal Respir 1983;11:58-9.

19 Costabel U, Bross KY, Burger D, Carlgren E, Guzman $\mathrm{J}$, Matthys $\mathrm{H}$. Prognostic value of helper cell counts in bronchoalveolar lavage fluid of pulmonary sarcoidosis. Am Rev Respir Dis 1983;suppl 4:62 (abstract).

20 Faure M, Nicolas JF, Gaucherand M, Czernielewski J, Mauduit G, Thivolet J. Numeration of T cell subsets in sarcoidosis using monoclonal antibodies: decreased levels of peripheral blood $T$ cells and cells with suppressor T cell phenotype. Dermatologica 1982; 165: 88-93.

21 Slade JD, Hepburn B. Prednisone-induced alterations of circulating human lymphocyte subsets. J Lab Clin Med 1983;101:479-87.

22 Faguet GB. Cellular immunity in sarcoidosis: evidence for an intrinsic defect of effector cell function. $A m R e v$ Respir Dis 1978;118:89-96.

23 Mangi RJ, Dwyer JM, Kantor FS. The effect of plasma upon lymphocyte response: in vitro demonstration of a humoral inhibitor in patients with sarcoidosis. Clin Exp Immunol 1974;18:519-28.

24 Daniele RP, Rowlands DT. Antibodies to T cells in sarcoidosis. Ann NY Acad Sci 1976;278:88-110.

25 Williams JD, Smith MD, Davies BH. Interaction of immune complexes and $\mathrm{T}$-suppressor cells in sarcoidosis. Thorax 1982;37:602-6.

26 Goodwin JS, DeHoratius R, Israel M, Peake GT, Messner RP. Suppressor cell function in sarcoidosis. Ann Intern Med 1979;90:169-73. 